\title{
Popular extreme sea level metrics can better communicate impacts
}

\author{
D. J. Rasmussen ${ }^{1}$ (D) . Scott Kulp ${ }^{2} \cdot$ Robert E. Kopp $p^{3,4}$ (D) $\cdot$ Michael Oppenheimer ${ }^{1,5,6}$ (D) . \\ Benjamin H. Strauss ${ }^{2}$ (D)
}

Received: 1 October 2020 / Accepted: 3 December 2021 /Published online: 15 February 2022

(C) The Author(s) 2022

\begin{abstract}
Estimates of changes in the frequency or height of contemporary extreme sea levels (ESLs) under various climate change scenarios are often used by climate and sea level scientists to help communicate the physical basis for societal concern regarding sea level rise. Changes in ESLs (i.e., the hazard) are often represented using various metrics and indicators that, when anchored to salient impacts on human systems and the natural environment, provide useful information to policy makers, stakeholders, and the general public. While changes in hazards are often anchored to impacts at local scales, aggregate global summary metrics generally lack the context of local exposure and vulnerability that facilitates translating hazards into impacts. Contextualizing changes in hazards is also needed when communicating the timing of when projected ESL frequencies cross critical thresholds, such as the year in which ESLs higher than the design height benchmark of protective infrastructure (e.g., the 100 -year water level) are expected to occur within the lifetime of that infrastructure. We present specific examples demonstrating the need for such contextualization using a simple flood exposure model, local sea level rise projections, and population exposure estimates for 414 global cities. We suggest regional and global climate assessment reports integrate global, regional, and local perspectives on coastal risk to address hazard, vulnerability and exposure simultaneously.
\end{abstract}

Keywords Extreme sea level $\cdot$ Assessment reports $\cdot$ IPCC $\cdot$ Sea level rise $\cdot$ Impacts

D. J. Rasmussen

dj.rasmussen@princeton.edu

1 Princeton School of Public \& International Affairs, Princeton University, Princeton, NJ, USA

2 Climate Central, Princeton, NJ, USA

3 Department of Earth \& Planetary Sciences, Rutgers University, New Brunswick, NJ, USA

4 Institute of Earth, Ocean, \& Atmospheric Sciences, Rutgers University, New Brunswick, NJ, USA

5 Department of Geosciences, Princeton University, Princeton, NJ, USA

6 High Meadows Institute, Princeton University, Princeton, NJ, USA 


\section{Introduction}

Extreme sea levels (ESLs) are short-lived (hours to days), exceptionally high local seasurface heights, usually resulting from coastal storms, waves, or astronomical tides (Gregory et al. 2019). Observational studies show that contemporary ESLs are occurring with increasing frequency, largely as a result of rising local mean sea level due to global warming and other non-climatic local factors (e.g., ground subsidence; Sweet and Park 2014; Dahl et al. 2017; Menéndez and Woodworth 2010). Future changes in ESL frequency pose significant hazards to coastal communities, natural resources, and ecosystem services (Oppenheimer et al. 2019). Potentially deadly and costly floods can occur in unprepared areas if ESLs overtop natural (e.g., dunes, cliffs) or engineered protection structures (e.g., seawalls, bulkheads, levees). Communicating the risks of changing ESLs can build trust between experts and the public, raise awareness, enhance the understanding of risks, develop agreement about policy options, and motivate pre-emptive risk reduction measures (Rowan 1991). In the case of coastal flooding, the latter includes purchasing flood insurance, elevating assets (e.g., regrading or placing homes on stilts), planning long-term land use strategies (e.g., coastal retreat) and implementing hard protection (Oppenheimer et al. 2019; Rasmussen et al. 2021). Projected changes in ESLs are also crucial for the design of new long-lived infrastructure projects, which can impact future exposure (Rasmussen et al. 2020).

Climate and sea level scientists have developed various metrics and indicators to describe changes in the frequency of contemporary ESLs under various climate change scenarios (Hunter 2012; Buchanan et al. 2017; Rasmussen et al. 2018; Frederikse et al. 2020; Vitousek et al. 2017; Taherkhani et al. 2020; Church et al. 2013; Howard and Palmer 2020; Feng et al. 2018; Fox-Kemper et al. 2021; Tebaldi et al. 2021). For example, ESL amplification factors (AFs; also called "factors of increase" or "multiplication factors") denote the change in the expected frequency of a given contemporary ESL under a given climate change scenario. ESL frequency AFs denote the expected relative increase in the number of threshold exceedances per year, the threshold usually being an arbitrary return level measured at a tide gauge. In addition to appearing in the primary peer-reviewed literature, ESL AFs have been used to communicate changes in ESLs to policy makers, stakeholders, and the general public in climate assessment reports, such as the Intergovernmental Panel on Climate Change's (IPCC) Sixth Assessment Report (AR6; Fox-Kemper et al. 2021), Special Report on Global Warming of $1.5{ }^{\circ} \mathrm{C}$ (SR1.5; Hoegh-Guldberg et al. 2018), Special Report on Oceans and the Cryosphere (SROCC; Oppenheimer et al. 2019), and the Fourth U.S. National Climate Assessment Report (U.S. NCA; Sweet et al. 2017).

Despite their wide-spread use, ESL AFs have a few notable limitations in communicating impacts at regional and global scales. First, ESL AFs only consider the hazard component of risk, that being the physical heights of water surfaces. They do not consider corresponding levels of exposure (e.g., population, property value, or natural resources), nor do they consider vulnerability. Some human settlements may be protected to a level above the elevation of the ESL in question (i.e., no flood occurs), or there may exist little to no exposure at or below the ESL height (i.e., a flood occurs, but there is no meaningful impact). Locally, ESLs AFs can be anchored to salient impacts on human systems and the natural environment, such as the frequency of overtopping existing flood defenses, roadway flooding, sewer or drainage back-ups, and the depth of the historically experienced high spring tide (often called a "King Tide"; e.g., Sweet et al. 2018). Without this local information, changes in ESL hazard provide no human or ecological context. Second, ESL AFs and other indicators (e.g., changes in return levels) are generally presented for arbitrary years (e.g., 2050, 
2100), which does not provide information about the likelihood of when impacts could cross critical thresholds for a particular location. Third, ESL AFs often highlight single return periods (e.g., the 1-in-100-year ESL, or an event comparable to a specific historic occurrence), potentially neglecting return periods that may be more salient for evaluation of risk for a given location.

In the remainder of this essay, we discuss each of these limitations and show that they can be overcome at regional or global scales. In light of the latter, we provide recommendations for communicating changes in ESLs in future climate assessment reports. Throughout, we use a simple flood exposure model to illustrate our points. Our methods are described in the Appendix.

\section{Contextualize extreme sea level frequency changes at global scales}

Unlike local analyses, regional- and global-scale assessments often do not anchor ESL AFs to impacts, leading to uninformative summary statements that provide little insight for risk communication. For example, the IPCC presently makes summary statements about ESL hazards at the global scale that are based on arbitrary water levels and are not anchored to specific events. This de-contextualizes changes in ESLs. More specifically, in Chapter 4 of the SROCC it is stated, "...extreme sea level event estimates as presented in [Section 4.2.3.4.1], clearly show that as a consequence of sea level rise, events which are currently rare (e.g., with an average return period of 100 years), will occur annually or more frequently at most available locations for RCP8.5 by the end of the century (high confidence)" (Oppenheimer et al. 2019), and also in Chapter 9 of AR6, "Due to relative sea level rise, extreme sea level events that occurred once per century in the recent past are projected to occur at least annually at more than half of all tide gauge locations by 2100 (high confidence)" (Fox-Kemper et al. 2021). While these statements may be true for the hazard, it provides no information about the event exposure or consequence, perhaps leaving the reader to infer that (1) such currently rare events will be destructive wherever they occur or (2) more frequent historical recurrence times are of little importance (e.g., tidal flood impacts that compound over time; Moftakhari et al. 2017).

For some locations, the contemporary 100-year ESL is impactful, but for other locations it is not. Here we illustrate "impact" as the percent of the 2010 total population of a city that resides on lands at or below the elevation of the 100-year ESL (contemporary or projected). For example, by 2070, the frequency of the contemporary 100-year ESL for San Juan (Puerto Rico) is projected to increase from 0.01 events/year to $>31$ events/year, on average, under a scenario in which global average surface air temperature (GSAT) stabilizes at $+2{ }^{\circ} \mathrm{C}$ above pre-industrial levels (an ESL AF of $\sim 3100$; Table 1; Fig. 1a). However, $<0.1 \%$ of the 2010 total population of San Juan, Puerto Rico $(<1,000$ out of 1.8 million people) resides on lands at or below the elevation of the contemporary 100-year ESL (Fig. 1b), as estimated using return levels from a local tide gauge and the bathtub flood modeling approach (see Appendix for details). The associated expected relative increase in population below the 100-ESL from projected SLR is $\sim 40 \%$ but is still $<1,000$ people in absolute terms. Overall, an increase in the frequency of the contemporary 100-year ESL will impact relatively few San Juan residents (assuming constant population). On the other hand, $\sim 2.3 \%$ of the total 2010 population of the Norfolk/Hampton Roads region of Virginia, USA ( $\sim 16,000$ out of 695,000 people), resides on lands below the elevation of the contemporary 100-year ESL, which is expected to occur more than three times per decade 


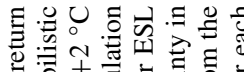

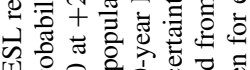

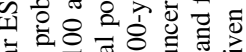

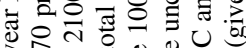

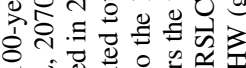

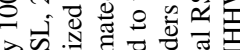

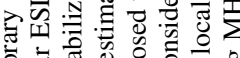

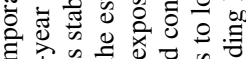

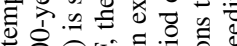

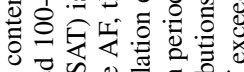

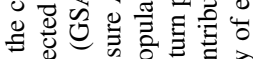

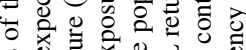

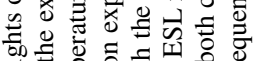

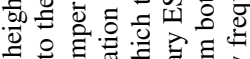

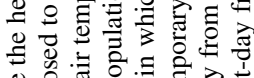

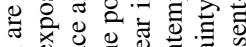

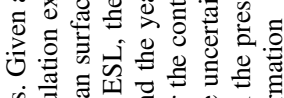
勺 ठํ.

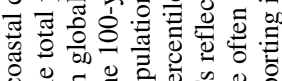
8.

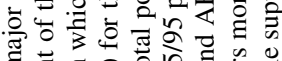
政.

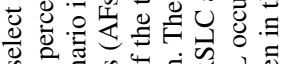

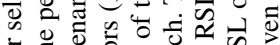

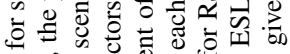
s

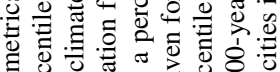

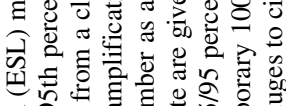
일.

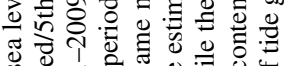

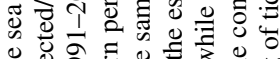

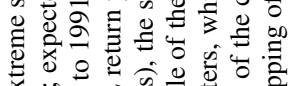

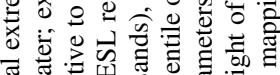

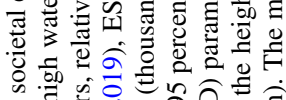

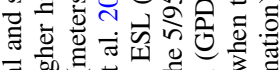

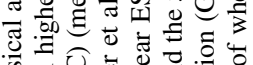

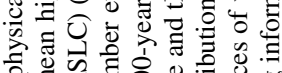

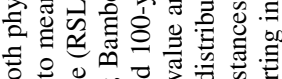
호은

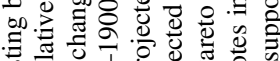

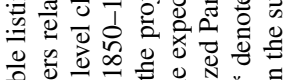

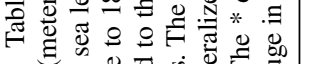

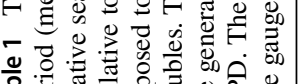

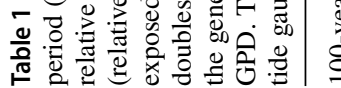

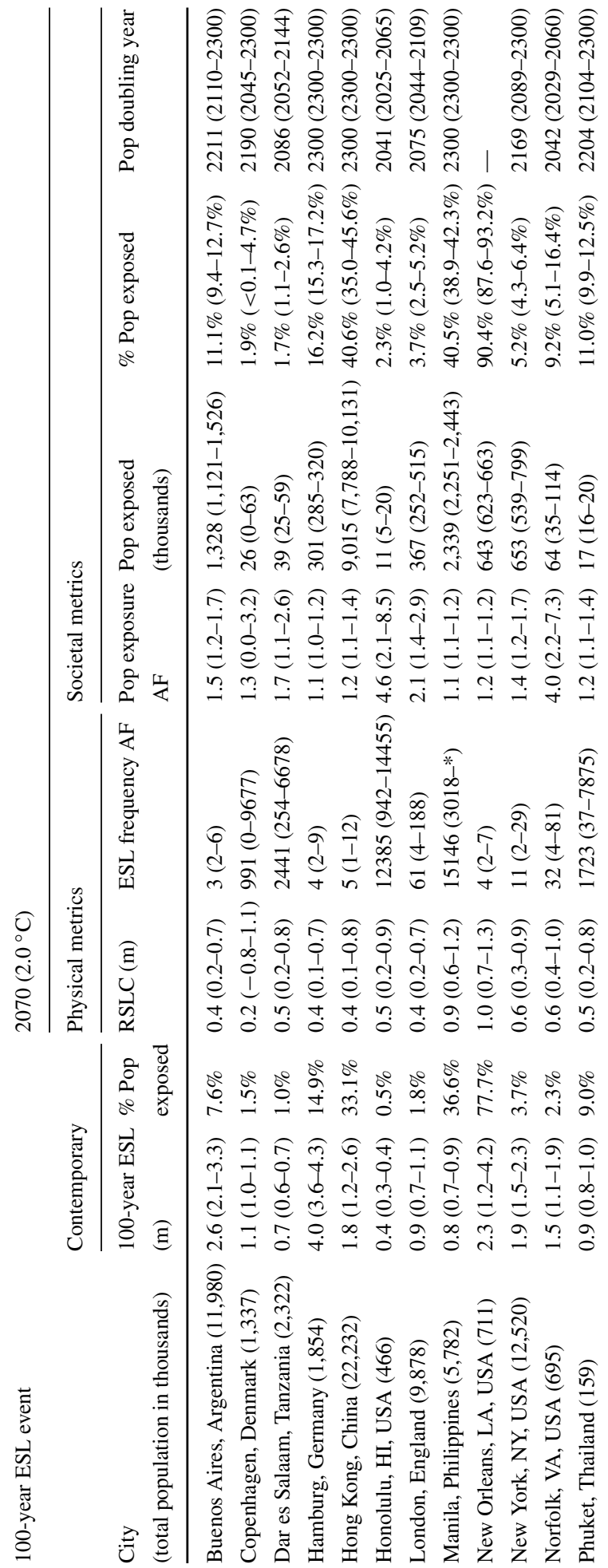




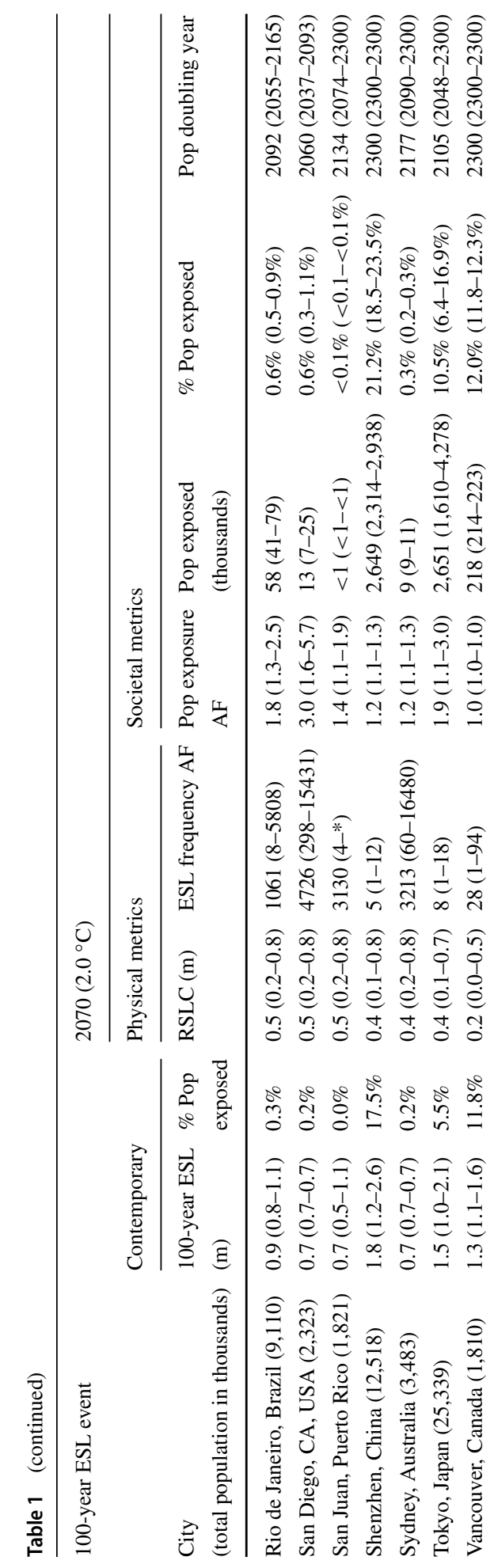



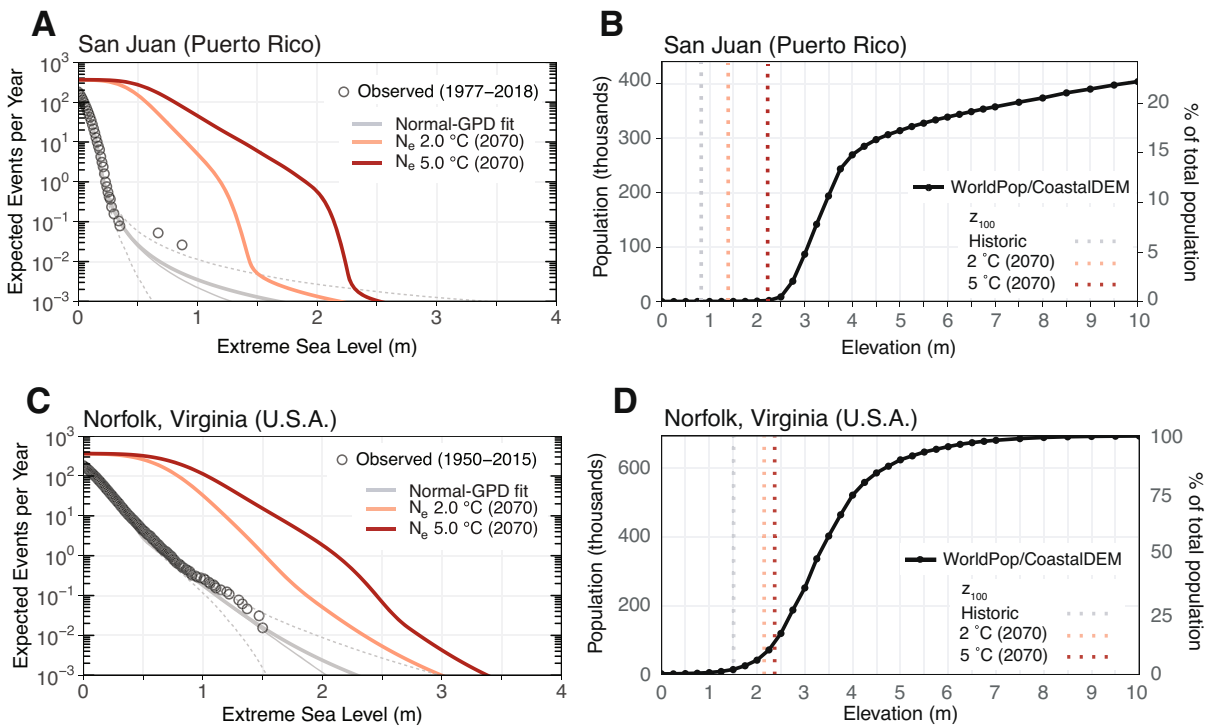

Fig. 1 a Expected number of contemporary extreme sea level (ESL) events per year as a function of ESL height (meters above local mean higher high water; MHHW) calculated by fitting a Normal-generalized Pareto distribution (GPD) probability mixture model to tide gauge observations (open gray circles) at San Juan (Puerto Rico) for 1991-2009 local mean sea level (thick gray line), expected number of projected ESL events per year as a functions of projected relative sea level change (RSLC) in 2070 under a scenario in which global mean surface air temperature (GSAT) is stabilized in 2100 at $+2{ }^{\circ} \mathrm{C}$ (orange line) and $+5{ }^{\circ} \mathrm{C}$ (red line; GSAT relative to 1850-1900). Thin gray lines are the contemporary ESL return curves for the 5/50/95 percentiles of the GPD parameter uncertainty range (dotted/solid/dotted lines, respectively). b A population exposure function that estimates the total population (left $y$-axis) and percent of total population (right $y$-axis) currently exposed as a function of ESL height (meters above MHHW) for San Juan (total population: 1.82 million). Filled black circles are population data from the 2010 WorldPop global gridded population database (Tatem 2017) applied to the elevation surfaces of CoastalDEM (Kulp and Strauss 2018). Linear interpolation is used to produce a continuous curve between the WorldPop data (black line). City boundaries are those as defined by Kelso and Patterson (2012) and may differ from actual administrative borders. Populations are assumed to remain constant in time. Denoted is the elevation of the contemporary 100-year ESL (gray), and the expected heights of the 100 -year ESL under a $+2{ }^{\circ} \mathrm{C}$ (orange) and $+5{ }^{\circ} \mathrm{C}$ (red) climate scenario. c as for A., but at a tide gauge at Sewell's Point, near Norfolk, Virginia (USA). d As for B., but for the Norfolk/Hampton Roads region of Virginia (USA; total population: 695,000)

by 2070 (ESL AF of 32; Table 1, Fig. 1d). Despite the ESL frequency AF for Norfolk being almost 100 times less than San Juan, the associated increase in population below the contemporary 100-year ESL is $\sim 3$ times larger (Fig. 1c, d; Table 1).

To illustrate this discrepancy globally, we consider both the expected change in the frequency of the contemporary 100-year ESL at tide gauges matched to 414 global cities (ESL frequency AF; Fig. 2a) and the expected relative change in number of people in each city currently residing on lands below the elevation of the contemporary 100-year ESL (the "population exposure AF"; Fig. 2b). We then group the cities by geographic region to look for regional patterns (Fig. 2c). Relationships between these metrics vary by city, in part due to differences in projected relative sea level change (RSLC; Gregory et al. 2019) and the shape of both the ESL return curves and the population versus elevation profiles (e.g., Fig. 1b, d). Across all regions, there is no strong relationship between changes in the frequency of the 100-year ESL and changes in population exposure to the 100-year event. 
A

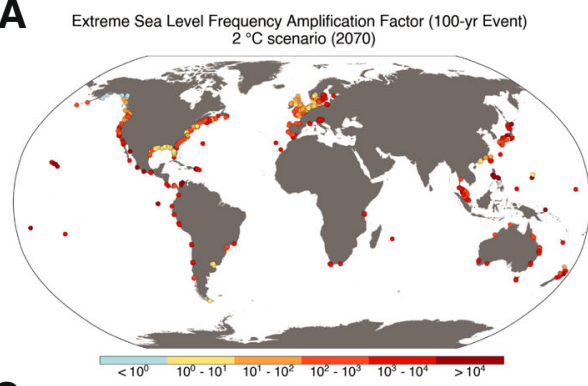

C
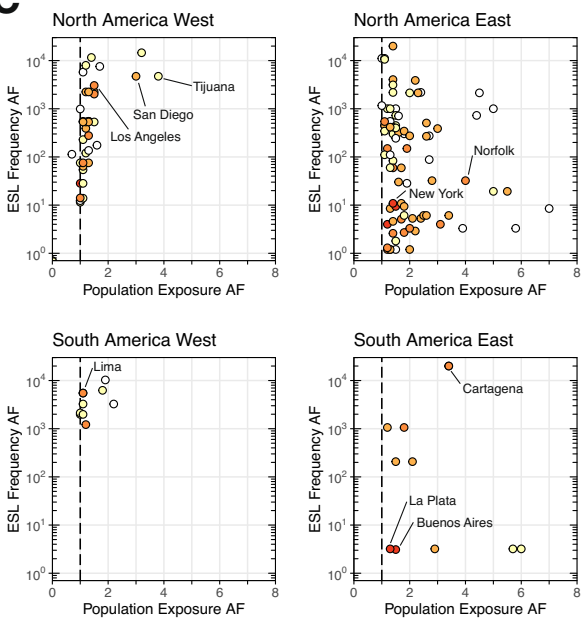

B Population Exposure Amplification Factor (100-yr Event) $2{ }^{\circ} \mathrm{C}$ scenario (2070)
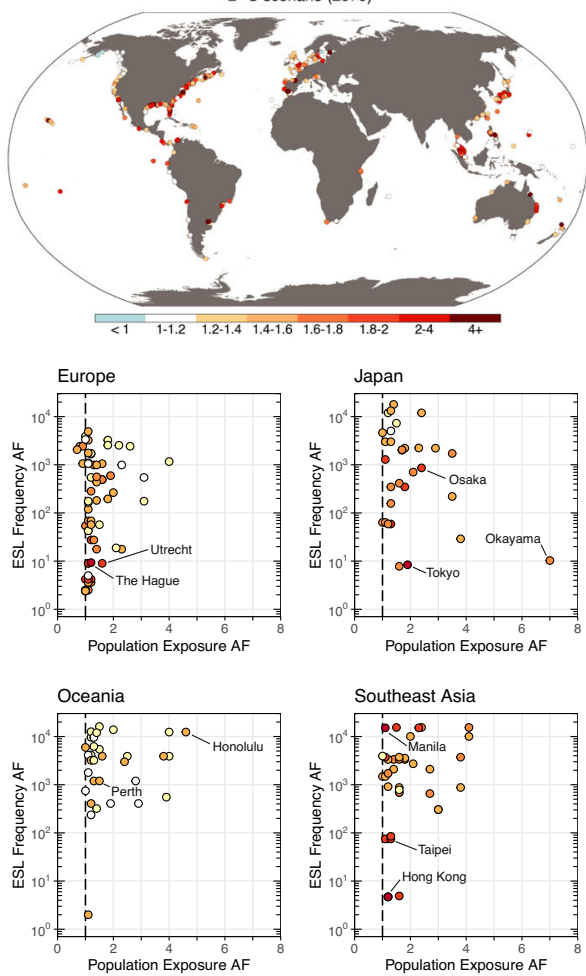

City Population Exposed to 100-yr ESL (2010)

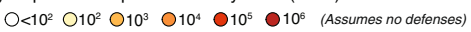

Fig. 2 A Extreme sea level (ESL) frequency amplification factors (AFs) for cities for 2070 under a climate scenario where the global mean surface air temperature is stabilized in 2100 at $+2{ }^{\circ} \mathrm{C}$ (relative to 1850 1900). B As for A, but for population exposure AFs. Populations are assumed to remain constant in time. A population exposure AF of 1 indicates no change in exposure. C ESL frequency AFs plotted against population exposure AFs for the 100-year ESL for 2070 for the same climate scenario as the maps. The 2010 population exposed to the contemporary 100-year ESL is indicated for each city. A list of the cities in each defined region is given in the supporting data files. Note that some cities may not appear in the scatter plots if (1) contemporary and projected population exposure to flood is zero, (2) the contemporary population exposure to flood is zero but projected exposure is non-zero (i.e., a population exposure AF of infinity), or (3) the population exposure $\mathrm{AF}$ is greater than two standard deviations from the mean of each region

Thus, ESL frequency AFs are, by themselves, poor proxies for impact, shown here in terms of total population below the elevation of the 100-year ESL event. Rather than a summary statement that considers only physical changes in ESL frequencies, one could-using this analysis - construct a statement that considers aggregate population exposure changes, "projected 2070 RSLC under an end-of-century $+2{ }^{\circ} \mathrm{C}$ GSAT stabilization scenario (relative to pre-industrial) is expected to at least double the 2010 population residing on lands below the 100-year ESL elevation for $25 \%$ of the 414 coastal cities assessed, growing to $37 \%$ under an end-of-century $+5{ }^{\circ} \mathrm{C}$ GSAT scenario." 
A

Median year in which population exposed to 100-yr ESL doubles

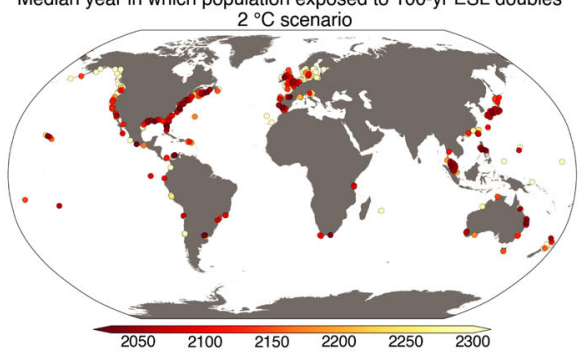

B $\%$ of Total Population Exposed (100-yr ESL) 2010 Population

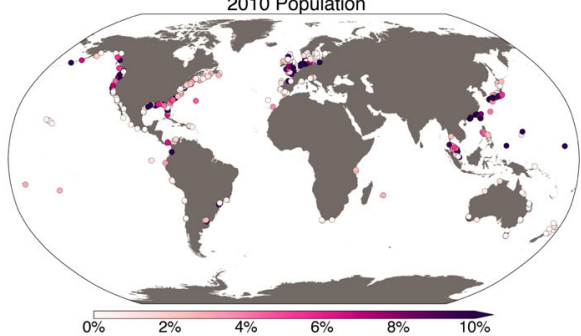

C

Year in which population exposed to 100 -yr ESL doubles $\left(2{ }^{\circ} \mathrm{C}\right.$ scenario) North America West

North America East
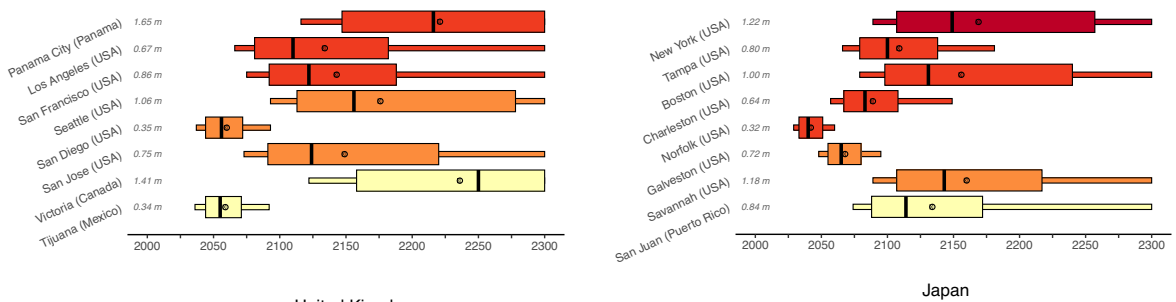

United Kingdom
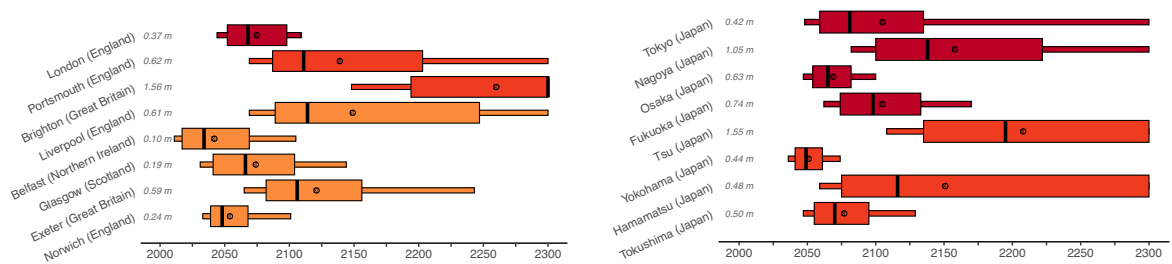

City Population Exposed to 100-yr ESL (2010)

$\square 10^{2} \square 10^{3} \square 10^{4} \quad \square 10^{5} \quad$ (Assumes no defenses)

Fig. 3 A Median projected year in which local relative sea level change (RSLC) doubles the population exposure to the contemporary 100-year extreme sea level (ESL) event (i.e., a population exposure amplification factor of 2; analysis assumes constant population) under a scenario in which global mean surface air temperature in 2100 is stabilized at $+2{ }^{\circ} \mathrm{C}$ (relative to $1850-1900$ ). B Percent of the total city population exposed to the contemporary 100-year ESL (assumes 2010 population). C As for A, but highlighting select cities to show the RSLC uncertainty as a box plot. The thinner boxes cover the 5/95 percentile of RSLC uncertainty while the thicker boxes cover the $17 / 83$ percentile. Black lines denote the 50th percentile and black dots denote the expected year. The RSLC amounts associated with each population exposure AF threshold are given in light gray (relative to 2000). The color of each box indicates the 2010 population exposure to the 100-year ESL (assumes no flood defenses)

\section{Communicate uncertainty in the timing of crossing impact-relevant thresholds}

Extreme sea level AFs are often presented for an arbitrary future year in which the projection uncertainty in RSLC is only considered for that particular year (e.g., 2050, 2070, 2100). However, also of interest is analyzing projection uncertainty in the rates of RSLC and how it impacts the timing of reaching ESL frequency benchmarks, such as the first year in which the contemporary 100-year ESL becomes the 1-year ESL. Just as with assessing ESL AFs for particular years, impactful communication of the timing of such benchmarks should be 
tied to relevant societal thresholds, rather than arbitrary water levels. Examples include the year in which ESLs higher than the design height benchmark of protective infrastructure (e.g., the 100-year water level) are expected to occur within the lifetime of that infrastructure (Rasmussen et al. 2020), or the population exposure associated with a given amount of RSLC. We use our simple ESL population exposure model to illustrate the latter.

The uncertainty in the timing of a doubling of the population exposed to the 100-year ESL is illustrated for several global cities under a $+2{ }^{\circ} \mathrm{C}$ scenario in Fig. 3 (all cities are given in the Supporting Data). Only uncertainty in the rates of RSLC are accounted for. For the Norfolk/Hampton Roads region, a doubling of the population exposure to the 100-year ESL ( $~ 16,000$ people, corresponding to a RSLC of $0.32 \mathrm{~m}$ ) is likely (17-83\% probability) to occur between 2033 and 2051 under a $+2{ }^{\circ} \mathrm{C}$ global mean temperature stabilization scenario (USA; Fig. 3c). For San Juan (Puerto Rico), a doubling of the population exposure to the 100 -year ESL is likely (17-83\% probability) to occur much later, between 2088 and 2172 (Fig. 3c).

While these analyses are local, they can be aggregated to regional or global scales to better inform aggregate statements about uncertainty in the timing of changes in ESLs. For example, using our analysis, a summary statement could be constructed that communicates uncertainty in the timing of population exposure doubling, "projected 2070 RSLC under an end-of-century $+2{ }^{\circ} \mathrm{C}$ GSAT stabilization scenario (relative to pre-industrial) is expected to at least double the 2010 population residing on lands at or below the elevation of the 100 -year ESL before 2100 at $27 \%$ of the 414 coastal cities assessed. This fraction grows to $54 \%$ under an end-of-century $+5{ }^{\circ} \mathrm{C}$ GSAT scenario." We note that considering population exposure produces drastically different summary statements from those given in SROCC that only consider the hazard, for example stating that "most" locations will experience the contemporary 100-year ESL annually by 2100 (see Section 2). Furthermore, as opposed to "many" localities experiencing the contemporary 100-year ESL annually by 2050 (as stated in SROCC), we find that under a $+2{ }^{\circ} \mathrm{C}$ GSAT scenario, $<7 \%$ of the 414 cities from this study are expected to experience a doubling of the population residing on lands at or below the elevation of the 100-year ESL before 2050 ( $\sim 12 \%$ under a $+5{ }^{\circ} \mathrm{C}$ GSAT scenario). The focus on a doubling of population exposure is an arbitrary example; other societal thresholds could be explored.

\section{Further suggestions for ways forward}

Extreme sea level (ESL) frequency amplification factors (AFs) are easy-to-calculate metrics that can help communicate flood and sea level rise risks when anchored to salient local events, such as the flooding of roadways, property, and other infrastructure (e.g., Sweet et al. 2018). However, stripped of their local context, ESL AFs only measure changes in arbitrary water levels at tide gauges that do not meaningfully aggregate to regional and global scales. In this essay, we have provided suggestions to improve ESL impact messaging in a regionalor global-scale assessment. We make some further remarks here as well as give suggestions for new research directions.

\subsection{The IPCC and other assessment reports should leverage exposure and vulnerability datasets}

To address the issue of contextualizing local ESL impacts at the global scale, we recommend the IPCC and other climate assessment reports integrate local exposure and vulnerability 
datasets that have global coverage into their quantitative analyses. Doing so will also facilitate constructing more definitive summary statements regarding ESL impacts. For example, the IPCC's SROCC "Summary for Policy Makers" gives a strong, but qualitative statement on projected ESL impacts, "[T]he increasing frequency of high water levels can have severe impacts in many locations depending on exposure" (IPCC 2019). Future IPCC assessments should consider coastal flood risk assessment approaches that consider local hazard, exposure, and vulnerability on global scales (e.g., Hallegatte et al. 2013; Abadie et al. 2017; Hanson et al. 2011).

In this essay we have suggested alternative and additional summary statements that could be constructed from population exposure datasets to add more context to projected changes in ESL frequencies (Sections 2 and 3). These are given as illustrative examples only. Employing sophisticated flood inundation modeling (e.g., Bates et al. 2021) and considering plausible socioeconomic shifts that affect exposure (e.g., population change from the Shared Socioeconomic Pathways or SSPs; O'Neill et al. 2014) could be used to construct similar statements. Because impacts can vary by return period, summary statements should also be made for both more frequent and rarer ESLs (e.g., the 10-year and 500-year ESLs, respectively).

While the inclusion of vulnerability and exposure data is possible for assessment reports that are designed to integrate changes in hazards with impacts (e.g., IPCC's SROCC, SR1.5, and SREX, the U.S. NCA), it is likely to be challenging (if not impossible) to implement in the IPCC's main assessment reports (e.g., AR6). This is because physical projections are separated from societal impacts by design, the former appearing in the Working Group 1 (WGI) report, ahead of societal impacts that are released roughly 6 months later in Working Group 2 (WGII). Because of this separation, changes in hazards are inherently provided without context until the WGII report is released. In the interim period between these two reports, scientists, the media, and the public are forced to make subjective judgements about the impacts of these hazard changes without their explicit quantification. Potential solutions include tighter integration among working groups in future assessment cycles (e.g., through the assignment of WGI or WGII advisors to WGII and WGI, respectively) or using Special Reports more often, the chapters of which are often more integrated than of those from the main assessment reports (e.g., Chapter 4 from SROCC).

\subsection{Create and maintain new publicly available exposure and vulnerability datasets}

New and existing datasets of terrain and flood protection elevation can help meet the needs of global assessment reports that seek to contextualize hazards. However, if there are gaps in the literature regarding these data, assessment reports are unlikely to fill the need on their own. Some existing datasets could help. The continually updated Dynamic and Interactive Vulnerability Assessment database (DIVA) is a popular source of vulnerability and exposure data for global-scale coastal flood risk assessments (Vafeidis et al. 2008; Hinkel et al. 2014; Brown et al. 2016; Kirezci et al. 2020; Jevrejeva et al. 2018; Muis et al. 2016; Wolff et al. 2016). This includes socioeconomic data such as capital stock, tourism, and adaptation costs as well as ecological information such as coastal land type (e.g., wetlands, mangroves, beach) and erosion rates (Hinkel and Klein 2009). However, most DIVA studies are economically oriented (e.g., appraising various adaptation approaches using benefit-cost analyses) and consider country- or regional-level entities (the notable exception is Hallegatte et al. 2013). City-level information is arguably more relevant for informing decisions in countries that divide political power between local, state/provincial, and national levels (Den Uyl and Russel 2018; Glicksman 2010; Peterson 1981). Furthermore, to our knowledge, DIVA is 
not publicly available. Therefore, it cannot be used for new integrative analyses done by the IPCC (see the FAIR data principles, Wilkinson et al. 2016; Juckes et al. 2020).

Large uncertainties in global exposure assessments are associated with the accuracy of digital elevation models (DEMs). New near-global-scale DEMs have provided increased accuracy for population exposure assessments (e.g., CoastalDEM, MERIT, and NASADEM; Kulp and Strauss 2019; Yamazaki et al. 2017). In the USA, where high accuracy data derived from airborne lidar exists for which to validate these products, CoastalDEM's reported vertical error as measured by the root-mean squared error (RMSE) is $2.4 \mathrm{~m}$, with considerable spatial variability. Given the importance of DEMs in flood risk assessment (McClean et al. 2020), further DEM accuracy improvements for these products are needed (Hinkel et al. 2021; Gesch 2018). CoastalDEM, ${ }^{1}$ MERIT and NASADEM are publicly available.

Exposure is not always a good proxy for impacts, particularly in densely built environments where flood protection plays a significant role. Several populations living in low-lying areas around the world (e.g., deltaic regions) are protected by flood protection such as levees, seawalls, and deliberately raised structures (e.g., buildings on stilts; Scussolini et al. 2016; Nicholls et al. 2019). Just like previous flood exposure studies (Neumann et al. 2015; Hanson et al. 2011; Kulp and Strauss 2019; McGranahan et al. 2007; Jongman et al. 2012; Lichter et al. 2011), our exposure estimates do not account for these protection tactics because they can be overtopped and breached. While this omission is common practice in exposure assessment (McClean et al. 2020), it is not always apparent to policy makers, stakeholders, and decision-makers who must interpret such information. In some cases, it has caused confusion from a communications standpoint (e.g., Mussen 2021). While some efforts have been made, ${ }^{2}$ a spatially explicit global database with flood protection footprints, elevations/protection levels, and failure rates remains elusive (Hinkel et al. 2021).

Lastly, while population exposure is highlighted in this essay as a viable metric to communicate ESL impacts, all ESL metrics have limitations in terms of what impacts they communicate. For example, population exposure metrics that are a percent of the total city population ignore absolute numbers of people. Population vulnerability should be considered, including accounting for those who are least able to evacuate a flood event based on age, disability, poverty, and other cause of immobility (e.g., Hurricane Katrina, Eisenman et al. 2007). Other metrics with policy-relevance include projected increases in disaster aid and flood insurance claims, the credit worthiness of municipalities, and metrics that estimate when recovery from major floods begins to be cut short by new events (e.g., Otto et al. 2021). For example, despite Hurricane Sandy having occurred over eight years ago, the New York Metropolitan Transit Authority just completed repairing the damage suffered by New York City's subway system (Mass Transit Magazine 2021). New research and publicly available datasets are needed in order to highlight these impacts. Advancements could be made through collaborations among researchers in climate adaptation, disaster risk management, and other relevant fields. Ultimately, the choice of which indicators and thresholds

\footnotetext{
${ }^{1}$ The 90 -m resolution version only

${ }^{2}$ Hallegatte et al. (2013) give upper and lower estimates of flood protection for over 100 major cities around the world based on surveyed responses from local experts. But this list is incomplete, these responses have not been verified, and local protection can also vary within a city. Tiggeloven et al. (2020) use the FLOPROS modeling approach (Scussolini et al. 2016) to estimate flood protection, but these calculations have not been locally verified.
} 
to highlight is subjective and depends on what stakeholders, the public, and policy makers view as being the most relevant for their needs.

Supplementary Information The online version contains supplementary material available at https://doi.org/10.1007/s10584-021-03288-6.

Acknowledgements The authors acknowledge the helpful comments from three anonymous reviewers. We thank William V. Sweet (NOAA) for stimulating conversations about the limitations of applying extreme sea level frequency amplification factors.

Funding D. J. R. was supported by both the Center for Policy Research on Energy and the Environment (CPREE) and the Science, Technology, and Environmental Policy (STEP) Program at Princeton University. R. E. K. was supported by grants from the National Science Foundation (ICER-1663807, DGE-1633557), the National Aeronautics and Space Administration (80NSSC17K0698 and JPL task 105393.509496.02.08.13.31), and from the Rhodium Group (for whom he has previously worked as a consultant) as part of the Climate Impact Lab consortium. S. K. and B. H. S. were supported by National Science Foundation (ICER-1663807), the National Aeronautics and Space Administration (80NSSC17K0698), and the V. Kann Rasmussen Foundation. M. O. was supported by the National Science Foundation grant 1520683.

Data availability The 3-arcsecond (90-m) version of CoastalDEM used in this analysis is available at no cost from Climate Central for non-commercial research use.

Code availability Code for generating sea level projections is available in the following repositories on Github: ProjectSL (https://github.com/bobkopp/ProjectSL) and LocalizeSL (https://github.com/bobkopp/ LocalizeSL). Code for generating extreme sea level projections is available in the following repositories on Github: hawaiiSL_process (https://github.com/dmr2/hawaiiSL_process), GPDfit (https://github.com/dmr2/ GPDfit), and return_curves (https://github.com/dmr2/return_curves).

Declarations The statements, findings, conclusions, and recommendations are those of the authors and do not necessarily reflect the views of the funding agencies.

Open Access This article is licensed under a Creative Commons Attribution 4.0 International License, which permits use, sharing, adaptation, distribution and reproduction in any medium or format, as long as you give appropriate credit to the original author(s) and the source, provide a link to the Creative Commons licence, and indicate if changes were made. The images or other third party material in this article are included in the article's Creative Commons licence, unless indicated otherwise in a credit line to the material. If material is not included in the article's Creative Commons licence and your intended use is not permitted by statutory regulation or exceeds the permitted use, you will need to obtain permission directly from the copyright holder. To view a copy of this licence, visit http://creativecommons.org/licenses/by/4.0/.

\section{References}

Abadie LM, Galarraga I, De Murieta ES (2017) Understanding risks in the light of uncertainty: lowprobability, high-impact coastal events in cities. Environ Res Lett 12:1. https://doi.org/10.1088/ 1748-9326/aa5254

Arns A, Dangendorf S, Jensen J et al (2017) Sea-level rise induced amplification of coastal protection design heights. Sci Rep 7(1):40,171. https://doi.org/10.1038/srep40171

Arns A, Wahl T, Wolff C et al (2020) Non-linear interaction modulates global extreme sea levels, coastal flood exposure, and impacts. Nat Commun 11(1):1918. https://doi.org/10.1038/s41467-020-15752-5

Bamber JL, Oppenheimer M, Kopp RE, Aspinall WP, Cooke RM (2019) Ice sheet contributions to future sea-level rise from structured expert judgment. Proc Nat Acad Sci 116(23):11,195-11,200. https://doi. org/10.1073/pnas.1817205116

Baranes HE, Woodruff JD, Talke SA et al (2020) Tidally driven interannual variation in extreme sea level frequencies in the Gulf of Maine. J Geophys Res: Oceans 125(10):e2020JC016,291. https://doi.org/10. 1029/2020JC016291 
Bates PD, Dawson RJ, Hall JW et al (2005) Simplified two-dimensional numerical modelling of coastal flooding and example applications. Coastal Eng 52(9):793-810. https://doi.org/10.1016/j.coastaleng. 2005.06.001, https://linkinghub.elsevier.com/retrieve/pii/S037838390500075X

Bates PD, Quinn N, Sampson C et al (2021) Combined modeling of US fluvial, pluvial, and coastal flood hazard under current and future climates. Water Resour Res 57(2):e2020WR028,673. https://doi.org/10. 1029/2020WR028673

Behrens CN, Lopes HF, Gamerman D (2004) Bayesian analysis of extreme events with threshold estimation. Stat Model 4(3):227-244. https://doi.org/10.1191/1471082X04st075oa

Breilh JF, Chaumillon E, Bertin X, Gravelle M (2013) Assessment of static flood modeling techniques: application to contrasting marshes flooded during Xynthia (western France). Nat Hazards Earth Syst Sci 13(6):1595-1612. https://doi.org/10.5194/nhess-13-1595-2013

Brown S, Nicholls RJ, Lowe JA, Hinkel J (2016) Spatial variations of sea-level rise and impacts: an application of DIVA. Clim Change 134(3):403-416. https://doi.org/10.1007/s10584-013-0925-y

Buchanan MK, Kopp RE, Oppenheimer M, Tebaldi C (2016) Allowances for evolving coastal flood risk under uncertain local sea-level rise. Climatic Change. https://doi.org/10.1007/s10584-016-1664-7

Buchanan MK, Oppenheimer M, Kopp RE (2017) Amplification of flood frequencies with local sea level rise and emerging flood regimes. Environ Res Lett 12:6. https://doi.org/10.1088/1748-9326/aa6cb3

Caldwell PC, Merrifield MA, Thompson PR (2015) Sea level measured by tide gauges from global oceans — the Joint Archive for Sea Level holdings (NCEI Accession 0019568). NOAA National Centers for Environmental Information Dataset

Church JA, Clark PU et al (2013) Chapter 13: Sea level change. In: Stocker TF, Qin D, Plattner GK et al (eds) Climate Change 2013: the Physical Science Basis. Cambridge University Press

Coles S (2001a) Classical extreme value theory and models. In: An introduction to statistical modeling of extreme values, Springer, chap 3

Coles S (2001b) An introduction to statistical modeling of extreme values. Springer, London. https://books. google.com/books?id=2nugUEaKqFEC, series Title: Lecture Notes in Control and Information Sciences

Coles S (2001c) Threshold models. In: An introduction to statistical modeling of extreme values. Springer, chap 4

Coles SG, Powell EA (1996) Bayesian methods in extreme value modelling: a review and new developments. International Statistical Review / Revue Internationale de Statistique 64(1):119-136. https://doi.org/10. 2307/1403426. publisher: [Wiley, International Statistical Institute (ISI)]

Coles SG, Tawn JA (1994) Statistical methods for multivariate extremes: an application to structural design. J R Stat Soc Series C (Appl Stat) 43(1):1-48. https://doi.org/10.2307/2986112. publisher: [Wiley, Royal Statistical Society]

Coles SG, Tawn JA (1996) Modelling extremes of the areal rainfall process. J R Stat Soc Series B (Methodol) 58(2):329-347. http://www.jstor.org/stable/2345980, publisher: [Royal Statistical Society, Wiley]

Cunnane C (1973) A particular comparison of annual maxima and partial duration series methods of flood frequency prediction. J Hydrol 18(3-4):257-271. https://doi.org/10.1016/0022-1694(73)90051-6

Dahl KA, Fitzpatrick MF, Spanger-Siegfried E (2017) Sea level rise drives increased tidal flooding frequency at tide gauges along the U.S. East and Gulf Coasts: Projections for 2030 and 2045. PLOS ONE 12(2):e0170,949. https://doi.org/10.1371/journal.pone.0170949, publisher: Public Library of Science

Davison AC, Smith RL (1990) Models for exceedances over high thresholds. J R Stat Soc Series B (Methodol) 52(3):393-442. http://www.jstor.org/stable/2345667, publisher: [Royal Statistical Society, Wiley]

Den Uyl RM, Russel DJ (2018) Climate adaptation in fragmented governance settings: the consequences of reform in public administration. Environ Poltics 27(2):341-361. https://doi.org/10.1080/09644016. 2017.1386341

DuMouchel WH (1983) Estimating The Stable Index $\$ \backslash$ alpha $\$$ in order to measure tail thickness: a critique. Ann Stat 11(4):1019-1031. https://doi.org/10.1214/aos/1176346318. https://projecteuclid.org/journals/ annals-of-statistics/volume-11/issue-4/Estimating-the-Stable-Index-alpha-in-Order-to-Measure-Tail/ 10.1214/aos/1176346318.full, publisher: Institute of Mathematical Statistics

Dupuis D (1998) Exceedances over high thresholds: a guide to threshold selection. Extremes 1(3):251-261

Egbert GD, Erofeeva SY (2002) Efficient inverse modeling of barotropic ocean tides. J Atmos Oceanic Tech 19(2):183-204. https://doi.org/10.1175/1520-0426(2002)019

Eisenman DP, Cordasco KM, Asch S, Golden JF, Glik D (2007) Disaster planning and risk communication with vulnerable communities: lessons from hurricane katrina. Am J Public Health 97(S1):S109-S115. https://doi.org/10.2105/AJPH.2005.084335

Embrechts P, Klüppelberg C, Mikosch T (1997) Modelling extremal events. Springer, Berlin. https://doi.org/ 10.1007/978-3-642-33483-2 
Familkhalili R, Talke SA (2016) The effect of channel deepening on tides and storm surge: a case study of Wilmington, NC. Geophys Res Lett 43(17):9138-9147. https://doi.org/10.1002/2016GL069494

Farr TG, Rosen PA, Caro E et al (2007) The shuttle radar topography mission. Rev Geophys 45:2. https:// doi.org/10.1029/2005RG000183

Feng J, Li H, Li D et al (2018) Changes of extreme sea level in 1.5 and $2.0^{\circ} \mathrm{C}$ warmer climate along the Coast of China. Front Earth Sci 6:216. https://doi.org/10.3389/feart.2018.00216, https://www.frontiersin.org/ article/10.3389/feart.2018.00216/full

Fox-Kemper B, Hewitt HT, Xiao C et al (2021) Chapter 9: ocean, cryosphere and sea level change. In: Masson-Delmotte V, Zhai P, Pirani A et al (eds) Climate Change 2021: the physical science basis. Contribution of Working Group I to the Sixth Assessment Report of the Intergovernmental Panel on Climate Change. Intergovernmental Panel on Climate Change (IPCC)

Frederikse T, Buchanan MK, Lambert E et al (2020) Antarctic Ice Sheet and emission scenario controls on 21 st-century extreme sea-level changes. Nat Commun 11(1):1-11. https://doi.org/10.1038/ s41467-019-14049-6

Gallien T (2016) Validated coastal flood modeling at Imperial Beach, California: comparing total water level, empirical and numerical overtopping methodologies. Coast Eng 111:95-104. https://doi.org/10.1016/j. coastaleng.2016.01.014, https://linkinghub.elsevier.com/retrieve/pii/S0378383916300059

Garner AJ, Mann ME, Emanuel KA et al (2017) Impact of climate change on New York City's coastal flood hazard: increasing flood heights from the preindustrial to 2300 CE. PNAS, 1-6. https://doi.org/10.1073/ pnas. 1703568114

Gesch DB (2018) Best practices for elevation-based assessments of sea-level rise and coastal flooding exposure. Frontiers in Earth Science 6. https://doi.org/10.3389/feart.2018.00230, publisher: Frontiers

Ghanbari M, Arabi M, Obeysekera J, Sweet W (2019) A coherent statistical model for coastal flood frequency analysis under nonstationary sea level conditions. Earth's Future. https://doi.org/10.1029/2018EF001089

Glicksman RL (2010) Climate change adaptation: a collective action perspective on federalism considerations. Environ Law 40(4):1159-1193

Gregory JM, Griffies SM, Hughes CW et al (2019) Concepts and terminology for sea level: mean, variability and change, both local and global. Surv Geophys 40(6):1251-1289. https://doi.org/10.1007/ s10712-019-09525-z

Hallegatte S, Green C, Nicholls RJ, Corfee-Morlot J (2013) Future flood losses in major coastal cities. Nat Clim Change 3(9):802-806. https://doi.org/10.1038/nclimate1979

Hanson S, Nicholls R, Ranger N et al (2011) A global ranking of port cities with high exposure to climate extremes. Clim Change 104(1):89-111. https://doi.org/10.1007/s10584-010-9977-4

Hauer ME (2017) Migration induced by sea-level rise could reshape the us population landscape. Nat Clim Change 7(5):321-325. https://doi.org/10.1038/nclimate3271

Hauer ME, Evans JM, Mishra DR (2016) Millions projected to be at risk from sea-level rise in the continental United States. Nat Clim Chang (March). https://doi.org/10.1038/nclimate2961, http://www.nature.com/ doifinder/10.1038/nclimate2961

Hausfather Z, Peters GP (2020) Emissions - the 'business as usual' story is misleading. Nature 577(7792):618-620. https://doi.org/10.1038/d41586-020-00177-3

Hinkel J, Klein RJ (2009) Integrating knowledge to assess coastal vulnerability to sea-level rise: the development of the DIVA tool. Global Environ Change 19(3):384-395. https://doi.org/10.1016/j.gloenvcha. 2009.03.002, https://linkinghub.elsevier.com/retrieve/pii/S0959378009000247

Hinkel J, Lincke D, Vafeidis AT et al (2014) Coastal flood damage and adaptation costs under 21st century sea-level rise. Proc Natl Acad Sci USA 111(9):3292-7. https://doi.org/10.1073/pnas.1222469111

Hinkel J, Feyen L, Hemer M et al (2021) Uncertainty and bias in global to regional scale assessments of current and future coastal flood risk. Earth's Fut 9:7. https://doi.org/10.1029/2020EF001882

Hoegh-Guldberg O, Jacob D, Taylor M et al (2018) Impacts of $1.5^{\circ} \mathrm{C}$ of global warming on natural and human systems. In: Masson-Delmotte V, Zhai P, Pörtner HO et al (eds) Global Warming of $1.5^{\circ} \mathrm{C}$. An IPCC Special Report on the impacts of global warming of $1.5^{\circ} \mathrm{C}$ above pre-industrial levels and related global greenhouse gas emission pathways, in the context of strengthening the global response to the threat of climate change, sustainable development, and efforts to eradicate poverty. Cambridge, p 138

Howard T, Palmer MD (2020) Sea-level rise allowances for the UK. Environ Res Commun 2(3):035,003. https://doi.org/10.1088/2515-7620/ab7cb4

Hunter J (2012) A simple technique for estimating an allowance for uncertain sea-level rise. Clim Change 113:239-252. https://doi.org/10.1007/s10584-011-0332-1

Hunter JR, Woodworth PL, Wahl T, Nicholls RJ (2017) Using global tide gauge data to validate and improve the representation of extreme sea levels in flood impact studies. Global Planet Change 156:34-45. https:// doi.org/10.1016/j.gloplacha.2017.06.007 
IPCC (2019) Summary for policy makers. In: Pörtner HO, Roberts D, Masson-Delmotte V, et a (eds) IPCC Special Report on the Ocean and Cryosphere in a Changing Climate. Intergovernmental Panel on Climate Change (IPCC)

Jevrejeva S, Jackson LP, Grinsted A, Lincke D, Marzeion B (2018) Flood damage costs under the sea level rise with warming of $1.5^{\circ} \mathrm{C}$ and $2.0^{\circ} \mathrm{C}$. Environ Res Lett 13(074014):11. https://doi.org/10.1088/ 1748-9326/aacc76

Jongman B, Ward PJ, Aerts JCJH (2012) Global exposure to river and coastal flooding: long term trends and changes. Global Environ Change 22(4):823-835. https://doi.org/10.1016/j.gloenvcha.2012.07.004. http://www.sciencedirect.com/science/article/pii/S0959378012000830

Juckes M, Pirani A, Pascoe C et al (2020) Implementing FAIR principles in the IPCC assessment process in EGU general assembly conference abstracts. EGU General Assembly

Kelso NV, Patterson T (2012) World Urban Areas, LandScan, 1:10 million

Kirezci E, Young IR, Ranasinghe R et al (2020) Projections of global-scale extreme sea levels and resulting episodic coastal flooding over the 21st Century. Sci Rep 10(1):11,629. https://doi.org/10.1038/ s41598-020-67736-6. number: 1 Publisher: Nature Publishing Group

Kopp RE, Horton RM, Little CM et al (2014) Probabilistic 21st and 22nd century sea-level projections at a global network of tide gauge sites. Earth's Fut 2:383-406. https://doi.org/10.1002/2014EF000239

Kopp RE, Gilmore EA, Little CM et al (2019) Usable science for managing the risks of sea-level rise. Earth's Fut 7(12):1235-1269. https://doi.org/10.1029/2018EF001145

Kulp S, Strauss BH (2017) Rapid escalation of coastal flood exposure in US municipalities from sea level rise. Clim Change 142(3-4):477-489. https://doi.org/10.1007/s10584-017-1963-7

Kulp SA, Strauss BH (2018) CoastalDEM: a global coastal digital elevation model improved from SRTM using a neural network. Remote Sens Environ 206:231-239. https://doi.org/10.1016/j.rse.2017.12.026

Kulp SA, Strauss BH (2019) New elevation data triple estimates of global vulnerability to sea-level rise and coastal flooding. Nat Commun 10(1):4844. https://doi.org/10.1038/s41467-019-12808-Z

Lang M, Ouarda TBMJ, Bobée B (1999) Towards operational guidelines for over-threshold modeling. J Hydrol 225(3):103-117. https://doi.org/10.1016/S0022-1694(99)00167-5

Lichter M, Vafeidis AT, Nicholls RJ (2011) Exploring data-related uncertainties in analyses of land area and population in the "Low-Elevation Coastal Zone" (LECZ). J Coast Res 27(4):757-768. https://doi.org/10.2112/JCOASTRES-D-10-00072.1. https:// bioone.org/journals/journal-of-coastal-research/volume-27/issue-4/JCOASTRES-D-10-00072.

1/Exploring-Data-Related-Uncertainties-in-Analyses-of-Land-Area-and/10.2112/

JCOASTRES-D-10-00072.1.full

Little CM, Horton RM, Kopp RE et al (2015) Joint projections of US East Coast sea level and storm surge. Nat Clim Change 5(12):1114-1120. https://doi.org/10.1038/nclimate2801. http://www.scopus. com/inward/record.url?eid=2-s2.0-84948163996\&partnerID=tZOtx3y1

MacDonald A, Scarrott C, Lee D et al (2011) A flexible extreme value mixture model. Comput Stat Data Anal 55(6):2137-2157. https://doi.org/10.1016/j.csda.2011.01.005. https://linkinghub.elsevier.com/retrieve/ pii/S0167947311000077

Mass Transit Magazine (2021) MTA announces completion of Sandy Resiliency work in F Line's East River tunnel. https://www.masstransitmag.com/rail/infrastructure/press-release/21216884/mta-new-york-citytransit-mta-announces-completion-of-sandy-resil iency-work-in-f-lines-east-river-tunnel

McClean F, Dawson R, Kilsby C (2020) Implications of using global digital elevation models for flood risk analysis in cities. Water Resour Res 56(10):e2020WR028,241. https://doi.org/10.1029/2020WR028241

McGranahan G, Balk D, Anderson B (2007) The rising tide: assessing the risks of climate change and human settlements in low elevation coastal zones. Environ Urban 19(1):17-37. https://doi.org/10.1177/ 0956247807076960. publisher: SAGE Publications Ltd

Melet A, Meyssignac B, Almar R, Le Cozannet G (2018) Under-estimated wave contribution to coastal sea-level rise. Nat Clim Change 8(3):234-239. https://doi.org/10.1038/s41558-018-0088-y

Menéndez M, Woodworth PL (2010) Changes in extreme high water levels based on a quasi-global tidegauge data set. J Geophys Res: Oceans 115(10):1-15. https://doi.org/10.1029/2009JC005997, iSBN: 2156-2202

Merkens JL, Reimann L, Hinkel J, Vafeidis AT (2016) Gridded population projections for the coastal zone under the shared socioeconomic pathways. Global Planet Change 145:57-66. https://doi.org/10.1016/j. gloplacha.2016.08.009

Moftakhari HR, Salvadori G, AghaKouchak A, Sanders BF, Matthew RA (2017) Compounding effects of sea level rise and fluvial flooding. Proceedings of the National Academy of Sciences. https://doi.org/10. 1073/pnas.1620325114, http://www.pnas.org/content/early/2017/08/22/1620325114.abstract

Muis S, Verlaan M, Winsemius HC, Aerts JC, Ward PJ (2016) A global reanalysis of storm surge and extreme sea levels (1979-2014). Nat Commun 7:1-11. https://doi.org/10.1038/ncomms11969 
Muis S, Verlaan M, Nicholls RJ et al (2017) A comparison of two global datasets of extreme sea levels and resulting flood exposure. Earth's Fut 5(4):379-392. https://doi.org/10.1002/2016EF000430

Mussen M (2021) These iconic London tourist attractions could be underwater in 30 years, including the Houses of Parliament and Tate Britain. https://www.mylondon.news/news/zone-1-news/ iconic-london-tourist-attractions-could-20251869

Neumann B, Vafeidis AT, Zimmermann J, Nicholls RJ (2015) Future coastal population growth and exposure to sea-level rise and coastal flooding - A global assessment. PLoS One 10:3. https://doi.org/10.1371/ journal.pone. 0118571

Nicholls RJ, Hanson S, Herweijer C et al (2008) Ranking port cities with high exposure and vulnerability to climate extremes: exposure estimates. OECD Environment Working Papers No. 1 Organisation for Economic Co-operation and Development (OECD). Paris

Nicholls RJ, Hinkel J, Lincke D, van der Pol T (2019) Global investment costs for coastal defense through the 21st century. World Bank Policy Research Working Paper 8745, World Bank Group. http://documents.worldbank.org/curated/en/433981550240622188/ Global-Investment-Costs-for-Coastal-Defense-through-the-21st-Century

NOAA (2020) NOAA digital coast coastal lidar. https://coast.noaa.gov/digitalcoast/

O'Neill BC, Kriegler E, Riahi K et al (2014) A new scenario framework for climate change research: the concept of shared socioeconomic pathways. Clim Change 122:387-400. https://doi.org/10.1007/ s10584-013-0905-2

Oppenheimer M, Glavovic B, Hinkel J et al (2019) Chapter 4: sea level rise and implications for low lying islands, coasts and communities. In: Pörtner HO, Roberts D, Masson-Delmotte V et al (eds). IPCC Special Report on the Ocean and Cryosphere in a Changing Climate. Intergovernmental Panel on Climate Change (IPCC)

Otto C, Kuhla K, Geiger T, Schewe J, Frieler K (2021) Incomplete recovery to enhance economic growth losses from U.S. hurricanes under global warming. Preprint. https://doi.org/10.21203/rs.3.rs-654258/v1

Parker B, Hess K, Milbert D, Gill S (2003) A national vertical datum transformation tool. Sea Technol 44(9):10-15

Peterson PE (1981) City limits, 1st edn. University of Chicago Press, Chicago \& London

Pickens J (1975) Statistical inference using extreme order statistics. Ann Stat 3(1):119-131. https://doi.org/ $10.1214 / \mathrm{aos} / 1176343003$

Pugh D, Woodworth P (2014) Sea-level science: understanding tides, surges tsunamis and mean sea-level changes, 2nd edn. Cambridge University Press, Cambridge

Ramirez JA, Lichter M, Coulthard TJ, Skinner C (2016) Hyper-resolution mapping of regional storm surge and tide flooding: comparison of static and dynamic models. Nat Hazards 82(1):571-590. https://doi. org/10.1007/s11069-016-2198-z

Rasmussen DJ, Bittermann K, Buchanan MK et al (2018) Extreme sea level implications of $1.5^{\circ} \mathrm{C}, 2.0^{\circ} \mathrm{C}$, and $2.5^{\circ} \mathrm{C}$ temperature stabilization targets in the 21st and 22nd centuries. Environ Res Lett 034(3):040. https://doi.org/10.1088/1748-9326/aaac87

Rasmussen DJ, Buchanan MK, Kopp RE, Oppenheimer M (2020) A flood damage allowance framework for coastal protection with deep uncertainty in sea level rise. Earth's Fut 8:3. https://doi.org/10.1029/ 2019EF001340

Rasmussen DJ, Kopp RE, Shwom R, Oppenheimer M (2021) The political complexity of coastal flood risk reduction: lessons for climate adaptation public works in the U.S. Earth's Fut 9(2):e2020EF001, 575. https://doi.org/10.1029/2020EF001575

Rowan KE (1991) Goals, obstacles, and strategies in risk communication: a problem-solving approach to improving communication about risks. J Appl Commun Res 19(4):300-329. https://doi.org/10.1080/ 00909889109365311

Schindelegger M, Green JaM, Wilmes SB, Haigh ID (2018) Can we model the effect of observed sea level rise on tides? J Geophys Res: Oceans 123(7):4593-4609. https://doi.org/10.1029/2018JC013959

Scussolini P, Aerts JCJH, Jongman B et al (2016) FLOPROS: an evolving global database of flood protection standards. Nat Hazards Earth Syst Sci 16(5):1049-1061. https://doi.org/10.5194/nhess-16-1049-2016

Seenath A, Wilson M, Miller K (2016) Hydrodynamic versus GIS modelling for coastal flood vulnerability assessment: which is better for guiding coastal management? Ocean Coastal Manag 120:99-109. https:// doi.org/10.1016/j.ocecoaman.2015.11.019

Sobel AH, Camargo SJ, Hall TM et al (2016) Human influence on tropical cyclone intensity. Science 353(6296):242-246. https://doi.org/10.1126/science.aaf6574. http://science.sciencemag.org/ content $/ 353 / 6296 / 242$

Sweet WV, Park J (2014) From the extreme to the mean: acceleration and tipping points of coastal inundation from sea level rise. Earth's Fut 2(12):579-600. https://doi.org/10.1002/2014EF000272, 2014EF000272 
Sweet WV, Kopp RE, Weaver CP et al (2017) Global and regional sea level rise scenarios for the United States. Technical Report NOS CO-OPS 083, National Oceanic and Atmospheric Administration

Sweet WV, Dusek G, Obeysekera J, Marra JJ (2018) Patterns and projections of high tide flooding along the U.S. coastline using a common impact threshold. NOAA Tech. Rep. NOS CO-OPS 086 National Oceanic and Atmospheric Administration. Silver Spring

Taherkhani M, Vitousek S, Barnard PL et al (2020) Sea-level rise exponentially increases coastal flood frequency. Sci Rep 10(1):1-17. https://doi.org/10.1038/s41598-020-62188-4

Talke SA, Orton P, Jay DA (2014) Increasing storm tides in New York Harbor, 1844-2013. Geophys Res Lett 41(9):3149-3155. https://doi.org/10.1002/2014GL059574

Tatem AJ (2017) WorldPop, open data for spatial demography. Sci Data 4(1):1-4. https://doi.org/10.1038/ sdata.2017.4

Tebaldi C, Strauss BH, Zervas CE (2012) Modelling sea level rise impacts on storm surges along US coasts. Environ Res Lett 7:014,032. https://doi.org/10.1088/1748-9326/7/1/014032

Tebaldi C, Ranasinghe R, Vousdoukas M et al (2021) Extreme sea levels at different global warming levels. Nat Clim Change 11(9):746-751. https://doi.org/10.1038/s41558-021-01127-1

Tiggeloven T, de Moel H, Winsemius HC et al (2020) Global-scale benefit-cost analysis of coastal flood adaptation to different flood risk drivers using structural measures. Nat Hazards Earth Syst Sci 20(4):1025-1044. https://doi.org/10.5194/nhess-20-1025-2020. publisher: Copernicus GmbH

UNFCCC (2015) Report of the Conference of the Parties on its twenty-first session. Held in Paris from 30 November to 13 December 2015 UNFCCC

Vafeidis AT, Nicholls RJ, McFadden L et al (2008) A new global coastal database for impact and vulnerability analysis to sea-level rise. J Coast Res 244:917-924. https://doi.org/10.2112/06-0725.1

Vitousek S, Barnard PL, Fletcher CH et al (2017) Doubling of coastal flooding frequency within decades due to sea-level rise. Sci Rep 7(1):1-9. https://doi.org/10.1038/s41598-017-01362-7

Vousdoukas MI, Voukouvalas E, Mentaschi L et al (2016) Developments in large-scale coastal flood hazard mapping. Nat Hazards Earth Syst Sci 16(8):1841-1853. https://doi.org/10.5194/nhess-16-1841-2016

Wahl T, Haigh ID, Nicholls RJ et al (2017) Understanding extreme sea levels for broad-scale coastal impact and adaptation analysis. Nat Commun) 16:075. https://doi.org/10.1038/ncomms 16075

Walsh KJE, McBride JL, Klotzbach PJ et al (2016) Tropical cyclones and climate change. WIREs Clim Change 7(1):65-89. https://doi.org/10.1002/wcc.371

Wilkinson MD, Dumontier M, Aalbersberg IJ et al (2016) The FAIR guiding principles for scientific data management and stewardship. Sci Data 3(1):160,018. https://doi.org/10.1038/sdata.2016.18

Wolff C, Vafeidis AT, Lincke D, Marasmi C, Hinkel J (2016) Effects of scale and input data on assessing the future impacts of coastal flooding: An application of diva for the emilia-romagna coast. Front Marine Sci 3:41. https://doi.org/10.3389/fmars.2016.00041

Woodworth PL, Hunter JR, Marcos M et al (2016) Towards a global higher-frequency sea level dataset. Geosci Data J 3(2):50-59. https://doi.org/10.1002/gdj3.42

Xian S, Yin J, Lin N, Oppenheimer M (2018) Influence of risk factors and past events on flood resilience in coastal megacities: comparative analysis of NYC and Shanghai. Sci Total Environ 610-611:1251-1261. https://doi.org/10.1016/j.scitotenv.2017.07.229

Yamazaki D, Ikeshima D, Tawatari R et al (2017) A high-accuracy map of global terrain elevations. Geophys Res Lett 44(11):5844-5853. https://doi.org/10.1002/2017GL072874

Publisher's note Springer Nature remains neutral with regard to jurisdictional claims in published maps and institutional affiliations. 